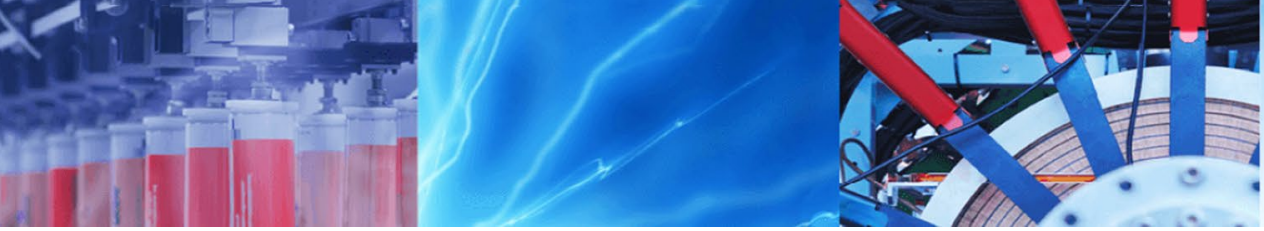

Research Article

\title{
Magnetic properties of graphene oxide via a simple mixing with waste engine oil-based carbon nanotubes
}

\author{
M. D. Nurhafizah ${ }^{1}$ iD
}

Received: 3 February 2020 / Accepted: 27 February 2020 / Published online: 3 March 2020

(c) Springer Nature Switzerland AG 2020

\begin{abstract}
Graphene oxide (GO) was synthesized via a simple electrochemical exfoliation of graphite in a surfactant-containing aqueous solution. A novel custom-made surfactant, 1,4-bis (neopentyloxy)-3-(neopentyloxycarbonyl)-1,4-dioxobutane2-sulfonate (TC14) was used to assist the exfoliation process. The structural and magnetic properties of prepared GO were examined using electron microscopies, micro-Raman, and Fourier transform infrared spectroscopies, and vibrating sample magnetometer (VSM). Room temperature VSM measurement showed a diamagnetic response of pristine GO under a high magnetic field. This indicated the low defect and the absence of any impurities in the synthesized GO. Simple mixing of GO and carbon nanotubes (CNTs) was also done to study their magnetic properties. CNTs were initially synthesized from waste engine oil using thermal chemical vapour deposition. It was found that the addition of magnetic CNTs has successfully induced the ferromagnetism in the GO sample. The saturation magnetization and average coercivity of GO/CNTs were observed to be 6.13 memu and $345.12 \mathrm{G}$, respectively. This study offers a low cost and simple method to induced magnetism in $\mathrm{GO}$ as compared to the common chemical modifications of GO.
\end{abstract}

Keywords Graphene oxide · Exfoliation · Electron microscopy · Carbon nanotubes · Magnetism

\section{Introduction}

Graphene has been known with its outstanding properties and wide range applications. A derivative of graphene namely graphene oxide $(\mathrm{GO})$ also has received enormous attention because it is easily synthesized, modified or chemically reduced for mass production of graphene and offers many practical applications. Graphene and its derivatives also show potential in spintronic applications due to their excellent carrier mobility and long spin diffusion length arise from the weak spin-orbit coupling of carbon atom [1, 2]. However, it is known that perfect graphene is intrinsically diamagnetic [1,3]. The presence of defects such as vacancies, impurity, dislocations and grain boundaries in graphene can induce the spin polarization and increase its magnetism [4, 5]. Hence, several studies have been done to enhance the magnetic properties of $\mathrm{GO}$ such as nanocomposite with metallic or magnetic materials [6, 7] and chemical activation [4]. Meanwhile, GO produced from the Hummers method and chemically reduced $\mathrm{GO}$ (RGO) was reported $[8,9]$ to show ferromagnetism response without any further treatments. It was believed that nature uses of acids during the synthesis process using Hummers method has contributed to the magnetic properties of $\mathrm{GO}$.

Modification of another carbon material namely carbon nanotubes (CNTs) is also seen can improve their properties and expand their applications. Pistone et al. [10] reported the synthesis of CNTs from isobutene using $\mathrm{Fe} / \mathrm{Al}_{2} \mathrm{O}_{3}$ based catalyst decorated with $\mathrm{Fe}_{3} \mathrm{O}_{4}$ magnetite nanoparticle. They use of metal-based catalyst and the addition of magnetite nanoparticle has successfully induced the

$\triangle$ M. D. Nurhafizah, mdnurhafizah@usm.my| ${ }^{1}$ Nano-Optoelectronics Research, Technology Laboratory, School of Physics, Universiti Sains Malaysia, 11800 Minden, Penang, Malaysia. 
magnetization in CNTs sample. Magnetic carbon materials offer many potential applications such as magnetic data storage, nanoprobe in magnetic force microscopy [10], adsorbent [11] and biosensor [12].

Moreover, the use of surfactant in stabilizing the carbon nanostructures also gained much attention due to its natural role of surfactant $[13,14]$. Previous works have implemented the triple-tails surfactant, TC14 in various nanocomposites applications including CNTs/natural rubber latex and graphene-based rubber [15-17]. However, so far, there is no work reported on the use of triple-tails surfactant, TC14 in the magnetic properties study of GO incorporated with CNTs.

Therefore, in this study, GO synthesized via an electrochemical exfoliation process was directly mixed with magnetic CNTs synthesized from waste engine oil (WEO) in the presence of ferrocene $\left(\mathrm{C}_{10} \mathrm{H}_{10} \mathrm{Fe}\right)$. A novel custom-made surfactant, 1,4-bis (neopentyloxy)3-(neopentyloxycarbonyl)-1,4-dioxobutane-2-sulfonate (TC14) [18] was used to assist the exfoliation process during the synthesis of $\mathrm{GO}$. The use of ferrocene catalyst did contribute to the magnetic properties of CNTs. As compared to the conventional routes to induce the magnetic properties of $\mathrm{GO}$, we offered a simpler, greener and cheaper process by avoiding the use of hazardous chemicals such as acid treatment. Moreover, the mixing of GO and CNTs which were both carbon-based materials did not give additional contaminations or impurities to the nanocomposite sample.

\section{Materials and methods}

GO was initially synthesized via an electrochemical exfoliation method as similarly reported in $[19,20]$. A custom-made surfactant, 1,4-bis (neopentyloxy)3-(neopentyloxycarbonyl)-1,4-dioxobutane-2-sulfonate (TC14) with concentration of $0.1 \mathrm{M}$ was used to assist the $\mathrm{GO}$ dispersion in deionized (DI) water. The graphite electrodes were connected to the voltage source of $7.0 \mathrm{~V}$ for $24 \mathrm{~h}$ synthesis process. CNTs were separately synthesized using thermal CVD method from waste engine oil as carbon source with a ferrocene catalyst of $17.99 \mathrm{wt} \%$ [21]. For the preparation of GO/CNTs sample, $0.05 \mathrm{~g}$ CNTs and $0.5 \mathrm{wt} \% \mathrm{TC} 14$ was dispersed in $10 \mathrm{ml}$ deionized water and stirred for $30 \mathrm{~min}$. GO solution was then simultaneously mixed into CNTs dispersion with volume ratio of $1: 1$ and sonicated for $30 \mathrm{~min}$ in an ultrasonic bath. The mixture was further stirred in a water bath system at $85^{\circ} \mathrm{C}$ for $1 \mathrm{~h}$. The prepared dispersion was then repeatedly centrifuged at $5000 \mathrm{rpm}$ and the precipitation was further dried in an oven to form a fine GO/CNTs powder. The samples were characterized using field emission scanning electron microscopy (FESEM-Hitachi SU 8020), high-resolution transmission electron microscopy (HRTEM- FEI Tecnai F30 200 kV), micro-Raman spectroscopy (Renishaw InVia Raman Microscope), Fourier transform infrared spectroscopy (FTIR-Thermo scientific Nicolet 6700 FTIR spectrometer), and vibrating sample magnetometer (VSM-LakeShore 7404).

\section{Result and discussion}

FESEM analysis was performed to observe the morphology of pristine GO, pure CNTs and GO/CNTs nanocomposites as seen in Fig. 1. Pristine GO (Fig. 1a) presented a lateral surface area, crumple, and typical wrinkle structure. The edges part exhibited a highly roll-up structure due to the intra-planar interaction between the layers of $\mathrm{GO}$ sheets [22]. Meanwhile, a dense quasi aligned CNTs from WEO precursor with a diameter at around $31-33 \mathrm{~nm}$ was presented in Fig. 1b. Hollow tube CNTs were observed to be covered between the crumple GO sheets in the GO/CNTs nanocomposite sample (Fig. 1c-d). The diameter of the CNTs in the GO/CNTs sample was consistent with pristine CNTs. The formed nanocomposites between GO and CNTs shows a thick flake-like shape with wrinkles and hollow tube structure similar to the reported of GO/CNTs composites [23]. However, both GO and CNTs structures were slightly deformed after the mixing process due to the stirring and sonication processes to produce a uniform $\mathrm{GO} /$ CNTs dispersion. This might be due to the $\pi-\pi$ bonding in-between CNTs and GO, thus altered the size of the nanostructures [22, 23].

The morphology of pristine GO and GO/CNTs nanocomposites was further investigated by high-resolution transmission electron microscopy (HRTEM) as shown in Fig. 2. Figure 2a shows a pristine $\mathrm{GO}$ consisted of multi-layers of graphene sheets ( $<10$ layers) due to its natural wavy and stacked characteristics. Meanwhile, GO/CNTs nanocomposites image in Fig. $2 \mathrm{~b}$ revealed the CNTs structure was distributed over the GO surfaces. It is clearly shown in all regions that the end-tubes of CNTs were pulled out from the GO structures, thus confirmed the nanocomposites are well-attached due to the higher compatibility of $\mathrm{GO}$ led by the stabilization of triple-tails surfactant within the nanocomposite.

Micro-Raman spectroscopy was used to investigate the carbon structure ordering of the sample (Fig. 3a). A typical micro-Raman spectrum of GO was observed with strong $D$ (disorder) and $G$ (graphitic) peaks at $~ 1359$ and $1597 \mathrm{~cm}^{-1}$, respectively and $I_{D} / I_{G}$ ratio of 0.91 . A slightly broad and intense peak at $1361 \mathrm{~cm}^{-1}$ was due to the defects contributed by the oxygenesis group at $\mathrm{GO}$ edges, indicating a successful oxidation and intercalation 

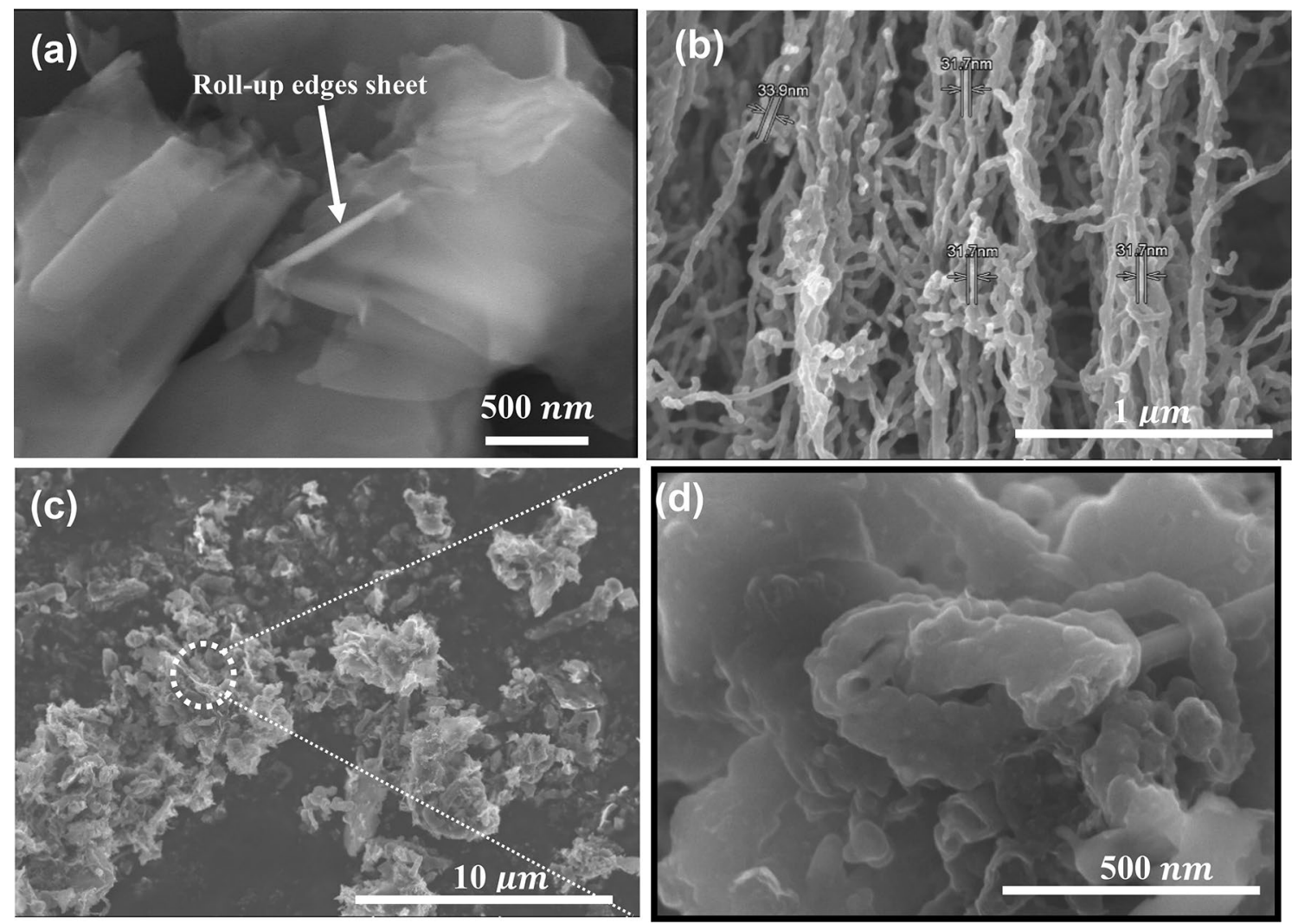

Fig. 1 FESEM images of a pristine GO, b WEO-based quasi aligned CNTs, c-d GO/CNTs nanocomposite sample
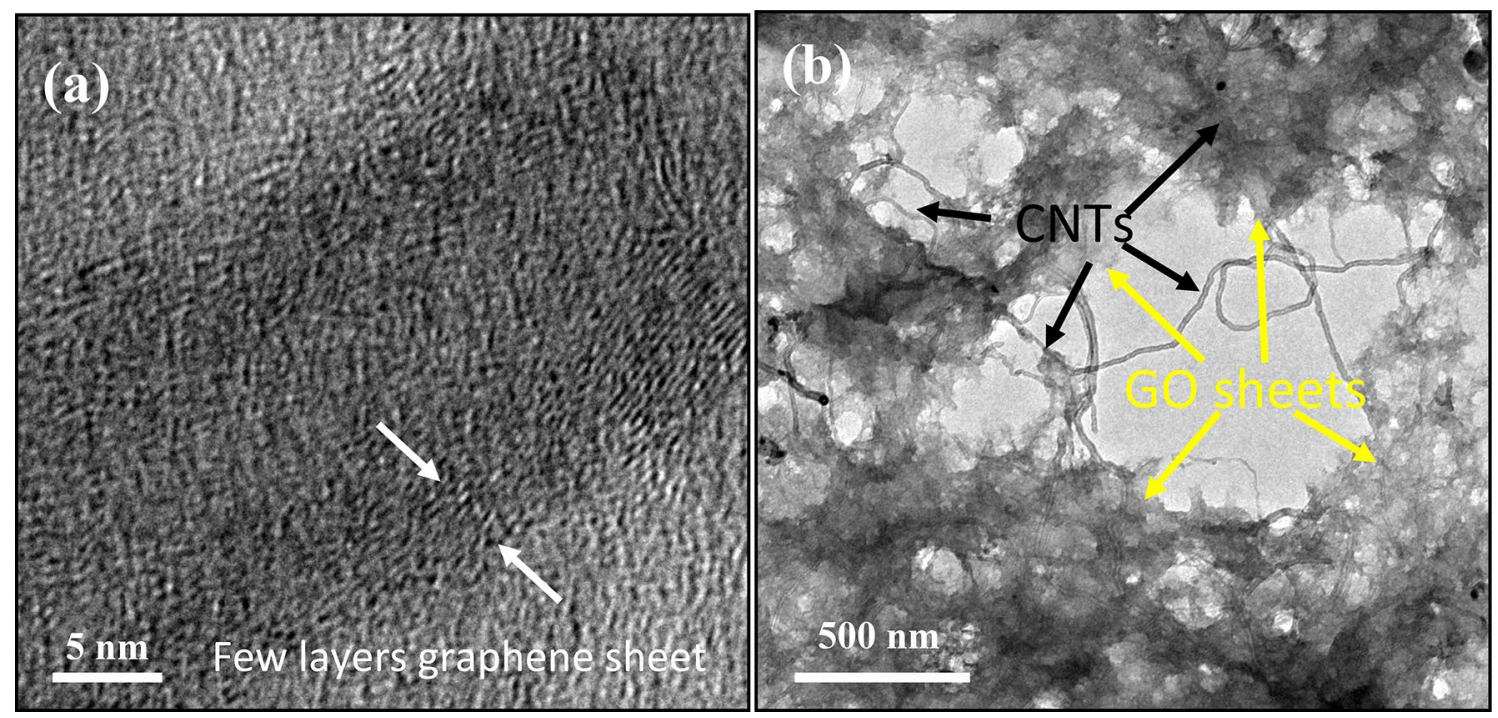

Fig. 2 HRTEM images of a pristine GO and $\mathbf{b}$ GO/CNTs

process [24]. Meanwhile, for CNTs synthesized from WEO, the $I_{D} / I_{G}$ ratio showed a slightly lower (0.90) than the GO sheets, which is consistent with the typical crystallinity of CNTs in previous work [21]. After the incorporation of GO and CNTs, the ratio was slightly increased up to 1.09 .
The distortion at $\mathrm{G}$ peak indicates the successful interactions between the GO and CNTs [24]. Higher disorder as also observed in FESEM analysis showed that the mixing process did affect the structure of the nanocomposite sample. 

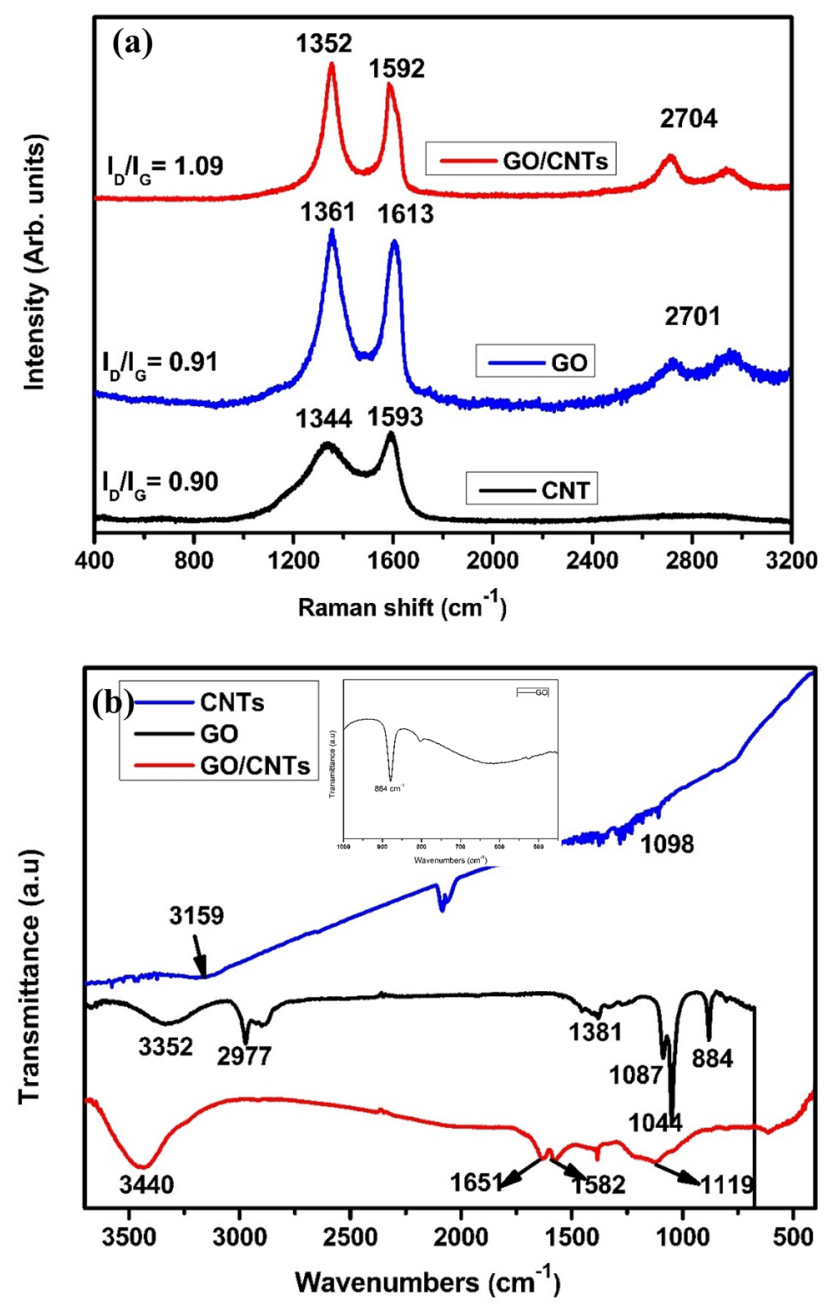

Fig. 3 a Micro-Raman and b FTIR spectra of pristine GO, pure CNTs and GO/CNTs samples

In order to affirm the attachment between CNTs and GO structures, the FTIR measurement was carried. From the FTIR analysis, the noticeable changes were observed at several points (Fig. 3b). As the previous report, there is no obvious peak presence in the CNTs spectrum [25]. Meanwhile, the characteristics peaks around 3352, 2977, $1381,1087,1044$ and $884 \mathrm{~cm}^{-1}$ were seen in the GO sample. The existence of the vibrational bands in the range of $1000-1400 \mathrm{~cm}^{-1}$ was due to the various oxygen functional groups attached at edges $\mathrm{GO}$ sheets $[26,27]$. Meanwhile, the peak appeared at around $800 \mathrm{~cm}^{-1}$ was confirmed the stabilized GO sheets assisted surfactant [28]. The presence of the intense and broad peaks at 2977 and $3352 \mathrm{~cm}^{-1}$, respectively, further supported that the GO solution is highly water- soluble [29]. After the addition of CNTs in the $\mathrm{GO}$ solution, the FTIR spectrum of GO/CNTs exhibits all characteristics peaks for $\mathrm{GO}$ along with several peaks of CNTs. The peaks at below $1000 \mathrm{~cm}^{-1}$ (epoxy group) for GO
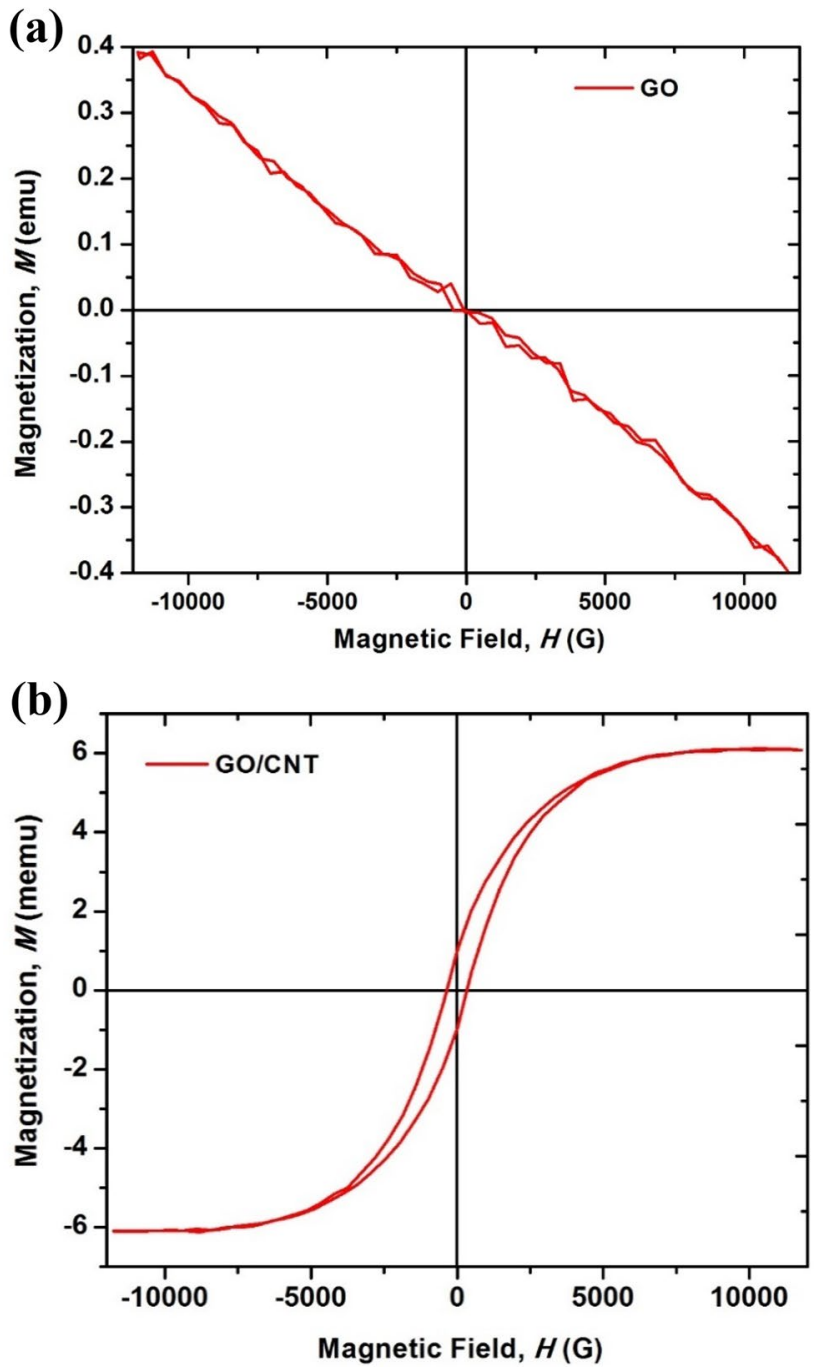

Fig. 4 Magnetic properties of $\mathbf{a} \mathrm{GO}$ and $\mathbf{b}$ GO/CNTs nanocomposites sample

and CNTs sample were disappeared in GO/CNTs nanocomposites meanwhile a broad and intense peak at $3440 \mathrm{~cm}^{-1}$ (hydroxyl group) was observed. This confirmed that the GO and CNTs are well-mixed during the mixing process. Meanwhile, the graphitic skeleton peak at 1582 and $1651 \mathrm{~cm}^{-1}$ further confirmed the functionalization between $\mathrm{GO}$ and CNTs [30, 31].

The magnetizations of the samples as the function of a magnetic field at room temperature are presented in Fig. 4. As reported in previous studies [4, 9], without any chemical modification and treatments, pristine GO was naturally diamagnetic. This is also consistent with our result (Fig. 4a) where the $\mathrm{GO}$ presented a diamagnetic response even under a high magnetic field up to $12,000 \mathrm{G}$. The addition of CNTs has successfully induced the magnetic properties of $\mathrm{GO}$ as seen in Fig. 4b. The ferromagnetic response was observed with the measured saturation magnetization 
and average coercivity of 6.13 memu and $345.12 \mathrm{G}$, respectively. Even though the results obtained is slightly lower but the magnetization value of $\mathrm{GO}$ composites is still comparable with other previous works [32, 33]. As previously reported, the CNTs exhibit ferromagnetic hysteresis with a saturation magnetization of $30 \mu e m u$ [34]. The enhancement observed for the GO/CNTs nanocomposite sample was probably due to the presence of metallocene catalyst (ferrocene) in CNTs. On the other hand, as presented through micro-Raman analysis, the increase of GO/CNTs defect also led to the enhancement of their magnetic properties. It was known that the presence of defects in carbonaceous materials such as graphene can induce spin polarization which can enhance the magnetic properties of the materials $[4,35,36]$.

\section{Conclusions}

Simple mixing of CNTs with GO has increased the magnetic properties of the GO-based nanocomposites. It was found that the addition of magnetic CNTs synthesized from wastes engine oil has successfully induced the ferromagnetism in the GO-assisted TC14 surfactant sample which suitably offers the nanocomposites in many sensors and photo-catalyst applications.

\begin{abstract}
Acknowledgements The authors would like to acknowledge Short Term Grant, Universiti Sains Malaysia (USM) (304/PFIZIK/6315241) for financial support. The authors want to thank Nano-Optoelectronics Research and Technology Laboratory (USM), Nanotechnology Research Centre (UPSI) for their facilities support, and Department of Frontier Material, Nagoya Institute of Technology, Japan for the technical supports.
\end{abstract}

Funding This study was funded by Short Term Grant, Universiti Sains Malaysia (USM) (Grant code: 304/PFIZIK/6315241).

\section{Compliance with ethical standards}

Conflict of interest The authors declare that they have no conflict of interest.

\section{References}

1. Tang T, Liu F, Liu Y, Li X, Xu Q, Feng Q (2014) Identifying the magnetic properties of graphene oxide. Appl Phys Lett 104:123104. https://doi.org/10.1063/1.4869827

2. Zhang P, Wu MW (2011) Electron spin diffusion and transport in graphene. Phys Rev B 84:045304. https://doi.org/10.1103/PhysR evB.84.045304

3. Sepioni M, Nair RR, Rablen S, Narayanan J, Tuna F, Winpenny R, Geim AK, Grigorieva I (2010) Limits on intrinsic magnetism in graphene. Phys Rev Lett 105:207205. https://doi.org/10.1103/ PhysRevLett.105.207205
4. Govind Raj K, Joy PA (2014) Ferromagnetism at room temperature in activated graphene oxide. Chem Phys Lett 605:89-92. https://doi.org/10.1016/j.cplett.2014.05.027

5. Raji AT, Lombardi EB (2015) Stability, magnetic and electronic properties of cobalt-vacancy defect pairs in graphene: a firstprinciples study. Phys Rev 464:28-37. https://doi.org/10.1016/j. physb.2015.02.017

6. Sahoo PK, Panigraphy B, Li D, Bahadur D (2013) Magnetic behavior of reduced graphene oxide/metal nanocomposites. J Appl Phys 113:17B525. https://doi.org/10.1063/1.4799150

7. Sun J, Liang Q, Han Q, Zhang X, Ding M (2015) One-step synthesis of magnetic graphene oxide nanocomposite and its application in magnetic solid phase extraction of heavy metal ions from biological samples. Talanta 132:557-563. https://doi. org/10.1016/j.talanta.2014.09.043

8. Sarkar SK, Raul KK, Pradhan SS, Basu S, Nayak A (2014) Magnetic properties of graphite oxide and reduced graphene oxide. Phys E 64:78-82. https://doi.org/10.1016/j.physe.2014.07.014

9. Qin S, Guo X, Cao Y, Ni Z, Xu Q (2014) Strong ferromagnetism of reduced graphene oxide. Carbon 78:559-565. https://doi. org/10.1016/j.carbon.2014.07.039

10. Pistone A, Lannazzo D, Fazio M, Celegato F, Barrera G, Tiberto $P$, Giordano A, Azzerboni B, Galvagno S (2014) Synthesis and magnetic properties of multiwalled carbon nanotubes decorated with magnetite nanoparticles. Phys Rev B 435:88-91. https:// doi.org/10.1016/j.physb.2013.11.015

11. Luo YB, Li X, Jiang XY, Cai BD, Zhu FP, Zhang HF, Chen ZG, Pang $Y Q$, Feng YQ (2015) Magnetic graphene as modified quick, easy, cheap, effective, rugged and safe adsorbent for the determination of organochlorine pesticide residues in tobacco. J Chromatogr A 1406:1-9. https://doi.org/10.1016/j.chroma.2015.05.066

12. Chen HC, Chen YT, Tsai RY, Chen MC, Chen SL, Xiao MC, Chen $\mathrm{CL}$, Hua MY (2015) A sensitive and selective magnetic graphene composite-modified polycrystalline-silicon nanowire field-effect transistor for bladder cancer diagnosis. Biosens Bioelectron 66:198-207. https://doi.org/10.1016/j.bios.2014.11.019

13. Mohamed A, Sagisaka M, Hollamby M, Rogers SE, Heenan RK, Dyer R, Eastoe J (2012) Hybrid $\mathrm{CO}_{2}$-philic surfactants with low fluorine content. Langmuir 28(15):6299-6306. https://doi. org/10.1021/la3005322

14. Mohamed A, Sagisaka M, Guittard F, Cummings S, Paul A, Rogers $\mathrm{SE}$ (2011) Low fluorine content $\mathrm{CO}_{2}$-philic surfactants. Langmuir 27(17):10562-10569. https://doi.org/10.1021/la2021885

15. Nurhafizah MD, Aziz AA, Suriani AB, Mohamed A, Soga T (2020) Low-temperature exfoliated graphene oxide incorporated with different types of natural rubber latex: electrical and morphological properties and its capacitance performance. Ceram Int 46(5):5610-5622. https://doi.org/10.1016/j.ceram int.2019.11.005

16. Nurhafizah MD, Suriani AB, Mohamed A, Soga T (2020) Effect of voltage applied for graphene oxide/latex nanocomposite produced via electrochemical exfoliation and its application as conductive electrodes. Diam Relat Mater 101:107624. https:// doi.org/10.1016/j.diamond.2019.107624

17. Mohamed A, Anas AK, Suriani AB, Azira AA, Sagisaka M, Brown P, Eastoe J, Kamari A, Hashim NH, Isa IM (2014) Preparation of multiwall carbon nanotubes (MWCNTs) stabilised by highly branched hydrocarbon surfactants and dispersed in natural rubber latex nanocomposites. Coll Polym Sci 292(11):3013-3023. https://doi.org/10.1007/s00396-014-3354-1

18. Mohamed A, Ardyani T, Suriani AB, Brown P, Hollamby M, Sagisaka M (2016) Graphene-philic surfactants for nanocomposites in latex technology. Adv Colloid Interface 230:54-69. https:// doi.org/10.1016/j.cis.2016.01.003

19. Nurhafizah MD, Suriani AB, Alfarisa S, Mohamed A, Isa IM, Kamari A, Hashim N, Aziz AA, Mahmood MR (2015) The synthesis of 
graphene oxide via electrochemical exfoliation method. Adv Mater Res Trans Tech Publ 1109:55-59. https://doi.org/10.4028/ www.scientific.net/AMR.1109.55

20. Nurhafizah MD, Khor SY, Tan KL, Soga T (2019) The synthesized reduced graphene oxide enhanced the capacitive behavior of activated carbon/PVA as potential electrode materials. J Nanostruct. https://doi.org/10.22052/jns.2019.196289.1919

21. Suriani AB, Alfarisa $S$, Mohamed A, Isa IM, Kamari A, Hashim N, Mamat MH, Mohamed AR, Rusop M (2015) Quasi-aligned carbon nanotubes synthesised from waste engine oil. Mater Lett 139:220-223. https://doi.org/10.1016/j.matlet.2014.10.046

22. Lee SP, Ali GAM, Algarni H, Chong KF (2019) Flake size-dependent adsorption of graphene oxide aerogel. J Mol Liq 277:175180. https://doi.org/10.1016/j.molliq.2018.12.097

23. Song G, Sun L, Li S, Sun Y, Fu Q, Pan C (2020) Synergistic effect of $\mathrm{Gr}$ and CNTs on preparing ultrathin Cu-(CNTs + Gr) composite foil via electrodeposition. Compos B Eng 187:107841. https:// doi.org/10.1016/j.compositesb.2020.107841

24. Abu Bakar NH, Gam A, Ismail J, Algarni H, Chong KF (2019) Size-dependent corrosion behavior of graphene oxide coating. Prog Org 134:272-280. https://doi.org/10.1016/j.porgc oat.2019.05.011

25. Ali SD, Hussain ST, Gilani SR (2013) Synthesis, characterization and magnetic properties of carbon nanotubes decorated with magnetic $\mathrm{M}^{\mathrm{II}} \mathrm{Fe}_{2} \mathrm{O}_{4}$ nanoparticles. Appl Surf Sci 271:118-124. https://doi.org/10.1016/j.apsusc.2013.01.140

26. Wang X, Dou W (2012) Preparation of graphite oxide (GO) and the thermal stability of silicone rubber/GO nanocomposites. Thermochim Acta 529:25-28. https://doi.org/10.1016/j. tca.2011.11.016

27. Gupta VK, Agarwal S, Sadegh H, Ali GAM, Bharti AK, Makhlouf ASH (2017) Facile route synthesis of novel graphene oxide- $\beta$ cyclodextrin nanocomposite and its application as adsorbent for removal of toxic bisphenol A from the aqueous phase. Mol Liq 237:466-472. https://doi.org/10.1016/j.molliq.2017.04.113

28. Mohamed A, Trickett SYC, Cummings S, Sagisaka M, Hudson L, Sandrine N, Dyer R, Rogers SE, Heenan RK, Eastoe J (2010) Universal surfactant for water, oils, and $\mathrm{CO}_{2}$. Langmuir 26(17):13861-13866. https://doi.org/10.1021/la102303q
29. Ali GAM, Makhlouf SA, Yusoff MM, Chong KF (2015) Structural and electrochemical characteristics of graphene nanosheets as supercapacitor electrodes. Rev Adv Mater Sci 41:35-43

30. Shah S, Pandey OP, Mohammed J, Srivastava AK, Gupta A, Basandrai D (2020) Reduced graphene oxide (RGO) induced modification of optical and magnetic properties of M-type nickel doped barium hexaferrite. J Sol-Gel Sci Technol. https://doi. org/10.1007/s10971-019-05210-0

31. Layek RK, Uddin ME, Kim NH, Tak Lau AK, Lee JH (2017) Noncovalent functionalization of reduced graphene oxide with pluronic F127 and its nanocomposites with gum Arabic. Compos B Eng 128:155-163. https://doi.org/10.1016/j.composites b.2017.07.010

32. Yuan L, Nujiang T, Xiangang W, Qian F, Ming L, Qinghua X, Fuchi $L$, Youwei D (2013) Realization of ferromagnetic graphene oxide with high magnetization by doping graphene oxide with nitrogen. Sci Rep 3:25566. https://doi.org/10.1038/srep02566

33. Try T, Fuchi L, Liu Y (2014) Identifying the magnetic properties of graphene oxide. Appl Phys Lett 104(12):123104-123109. https ://doi.org/10.1063/1.4869827

34. Friedman $A L$, Chun $H$, Jung YJ, Heiman $D$, Glaser ER, Menon $L$ (2010) Possible room-temperature ferromagnetism in hydrogenated carbon nanotubes. Phys Rev 81:115461. https://doi. org/10.1103/PhysRevB.81.115461

35. El-Khawas EH, Azab AA, Mansour AM (2020) Structural, magnetic and dielectric properties of reduced graphene oxide/ $\mathrm{La}_{0.9} \mathrm{Bi}_{0.1} \mathrm{FeO}_{3}$ nanocomposites. Mater Chem Phys 241:122335. https://doi.org/10.1016/j.matchemphys.2019.122335

36. Sun Y, Pan H, Zheng Y, Zhang K, Fu L, Chen J, Zhang W, Tang N (2020) The effect of thermal annealing on the magnetic properties of graphene oxide quantum dots. Appl Surf Sci 501:144234. https://doi.org/10.1016/j.apsusc.2019.144234

Publisher's Note Springer Nature remains neutral with regard to jurisdictional claims in published maps and institutional affiliations. 